\title{
Secondary mental healthcare in prisons in England and Wales: results of a postal questionnaire
}

\author{
Nick Kosky, ${ }^{1}$ Clifford Hoyle ${ }^{2}$
}

The Psychiatrist (2011), 35, 445-448, doi: 10.1192/pb.bp.110.033274

${ }^{1}$ Dorset Community Health Services, Dorchester; ${ }^{2}$ Offender Health South West, Bristol

Correspondence to Nick Kosky (nick.kosky@dorset-pct.nhs.uk)

First received 27 Oct 2010, final revision 25 Jan 2011, accepted 29 Jun 2011

\begin{abstract}
Aims and method Prison mental health inreach teams (PMHITs) were introduced in response to policy from 2003. This provision comes under the responsibility of the National Health Service. Service development and structure was not defined in policy. A total of 97 prisons of an estimated 100 known to have a PMHIT were targeted by postal questionnaire and responses covered 62 prisons. Team structures were captured in the data with specific regard to the number of available professional sessions.
\end{abstract}

Results Findings determine there is generally no correlation between input and prison capacity, although there was some evidence of correlation in the high secure (category A) estate and that the female estate was generally better served.

Clinical implications It is evident from this study that PMHITs have evolved piecemeal, with no clear standards or equity across the estate. This is of concern.

Declarations of interest None.
The prison system has provided institutional care to those with mental illness for longer than any other centrally funded service in the UK. Until 2003, this was delivered by directly employed prison healthcare staff, supported on a highly variable basis by visiting mental health professionals. Following earlier recommendations made in The Future Organisation of Prison Health Care, ${ }^{1}$ and its sibling paper, Changing the Outlook, ${ }^{2}$ prison mental health inreach teams (PMHITs) were introduced, and their provision has become the responsibility of the National Health Service (NHS). The original purpose of PMHITs was to deliver care equivalent to that offered by community mental health teams.

Specific guidance for these teams from the Department of Health for their remit and make-up has been missing, although an early focus on those prisoners with serious and enduring mental illness - taken in practice to mostly mean psychotic illness - was endorsed. The Royal College of Psychiatrists has produced guidance for psychiatrists about staffing levels within prisons. ${ }^{3}$ This guidance reflects the enormous psychiatric morbidity in prisons, with up to $10 \%$ of male prisoners with psychosis, $78 \%$ with a personality disorder and $75 \%$ with a mood or anxiety disorder in certain parts of the prison estate. On top of this there is incompletely quantified but frequent comorbidity with substance misuse. Morbidity figures are taken from the only comprehensive analysis available, completed by the Office for National Statistics (ONS) in 1997. ${ }^{4}$ The ONS data do try to quantify the range of morbidity across remand, convicted and female populations but do not consider security categorisation or age range. A comprehensive review of the needs of those with a mental disorder (and intellectual disability) completed by Lord Bradley ${ }^{5}$ in 2009 recommends updating and improving available data. This paper attempts to review the provision of secondary mental health services by analysing the results of a postal questionnaire.

\section{Method}

Work undertaken by Staffordshire PMHIT in 2009 had identified 97 PMHITs in operation. A questionnaire (see online supplement to this paper) enquiring about the makeup of secondary mental health services was sent to all prisons and young offender institutions where a PMHIT had been identified in England and Wales. Questionnaires were emailed to team leaders where email addresses were available; questionnaires were posted to those teams where email addresses were unavailable. The questionnaire asked about the make-up of any PMHIT operating in that establishment, the number of sessions (defined as a period of $3-4 \mathrm{~h}$ in the morning or afternoon) of psychiatric time available to the PMHIT, the professional make-up of the team and the number of sessions available from the nonpsychiatric members of the team. The questionnaire ended by asking about training offered by the team to prison staff. Questionnaires were re-sent twice to teams that did not respond. Data collection took place over a 4-month period, ending in September 2009.

\section{Results}

Fifty-five teams from the total number of 97 responded, covering 62 prisons in all. All questionnaires contained some usable information, although 11 were incompletely 


\begin{tabular}{lcc} 
Table 1 & $\begin{array}{l}\text { Key correlations between service provision and } \\
\text { elements of the prison estate }\end{array}$ \\
Correlation: & $\begin{array}{c}\text { Correlation: } \\
\text { psychiatric } \\
\text { sessions }\end{array}$ & $\begin{array}{c}\text { non-psychiatric } \\
\text { sessions }\end{array}$ \\
Capacity & 0.28 & 0.23 \\
\hline Overall & & \\
\hline Gender & 0.29 & 0.21 \\
Male & 0.56 & 0.91 \\
Female & & \\
Type & 0.54 & 0.18 \\
Youth offender institutes & 0.76 & 0.56 \\
Category A & 0.34 & 0.16 \\
Category B & -0.16 & 0.03 \\
Category C & -0.91 & 0.89 \\
Category D & &
\end{tabular}

filled in. Key results are shown in Table 1 in the form of correlations between the operating capacity of different elements of the prison estate and available sessions from the psychiatric and non-psychiatric members of teams.

For all but two of adult prisons, both Category A, psychiatric provision was substantially less than that recommended by the Royal College of Psychiatrists: that recommendation equates, in the methodology of this study, to one session per week per 50 inmates for Category B prisons, one session per week per 40 inmates for Category A prisons, and one session per week for 150 inmates in Category $\mathrm{C}$ or $\mathrm{D}$ prisons. The recommendations also state that there should be addiction and psychotherapy sessions available. This did not appear to be the case in any prison, although this may relate to the questionnaire used. Young offender institutions and juvenile establishments were not covered in this guidance.

The number of psychiatric sessions available to a prison was highly variable, ranging from 37 (delivered by four full-time equivalent staff) to none. There was no close relationship between psychiatric sessions and operating capacity of the prison when the estate was considered as a whole. This is shown in Fig. 1.

Breaking down the prison estate by security rating (Appendix) and operating capacity shows that across the different ratings there is little real correlation either (product moment correlation coefficient of 0.28), except for Category A establishments, where the overall correlation between operating capacity and psychiatry sessions was 0.76 .

Consideration of the relationship between size of team, as described by number of sessions (excluding medical sessions), and prison operating capacity also showed little correlation (0.23). As the correlation between psychiatric sessions and sessions from other team members is high (0.76), it is unlikely that any shortfall in psychiatric time is made up for by other team members.

Cutting the prison estate in other ways - adult or young offender, male or female - was also of interest. Mean psychiatry sessions available for the prison estate as a whole were one per week per 140 inmates; in the female-only estate, this figure rose to one session per week per 65 inmates; in the young offender estate it fell to one per 350, although the best-served prison overall was a young offenders institution. Again, there was no marked correlation between operating capacity and psychiatry sessions available (0.56 for women-only prisons, 0.54 for the young offender estate). The high correlations between team provision and operating capacity in the female and Category D estate are probably incidental, relating to small sample size. There was however, a trend to higher levels of provision with higher levels of security, at least within male prisons (Fig. 2).

Of the 78 psychiatrists identified as working in PMHITs in this survey, 44 were forensic and 25 general adult psychiatrists. Most of the service provision appeared to come from consultants. There was one long-term locum, five

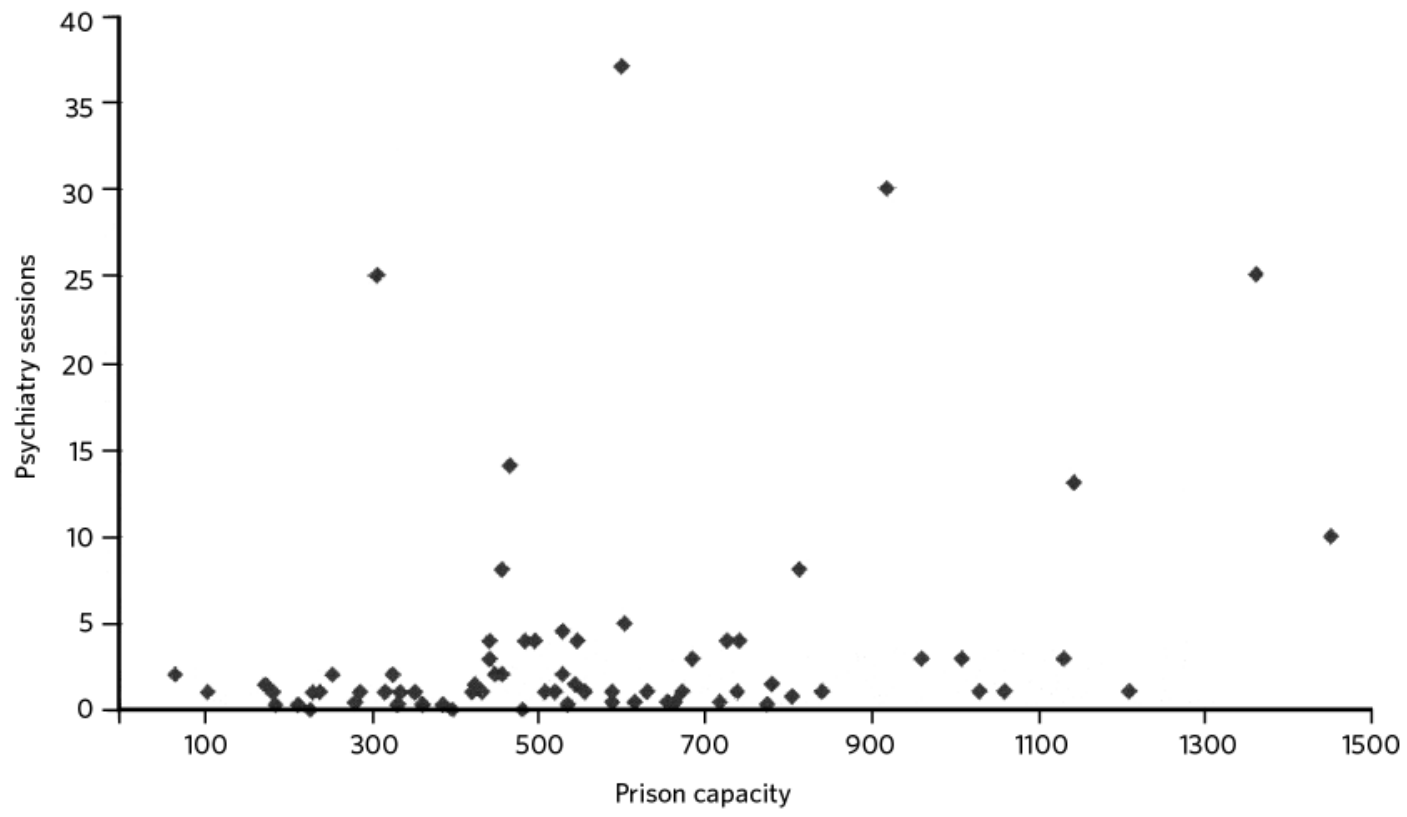

Fig. 1 Available psychiatry sessions against prison operating capacity. 


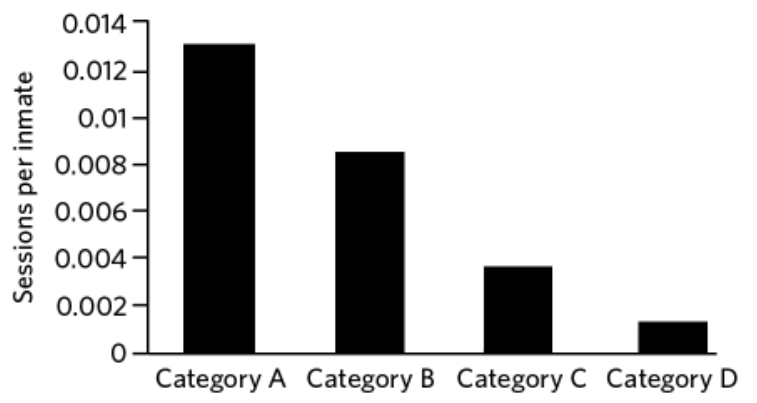

Fig. 2 Mean psychiatry sessions per inmate against prison category.

forensic child and adolescent mental health services (CAMHS) and three general CAMHS consultants recorded as having regular input. It was not possible to determine how many of these doctors worked full or part time in prisons; many appeared to cover more than one prison. The questionnaire did not enquire about the structure of their working week. One team had no doctor; one team had medical input from two general practitioners.

Make-up of PMHITs universally included nurses; 15 teams $(27.2 \%)$ were made up of nurses and doctors only; 19 (35.4\%) included psychologists, with inputs ranging from one session every 6 months to five sessions a week; 12 (21.8\%) included an occupational therapist or occupational therapist technician; $13(3.6 \%)$ a social worker; $3(5.4 \%)$ a support time and recovery worker; 2 (3.6\%) healthcare assistants (one in an administrative role). Four (7.2\%) teams had therapists, the more precise nature of which was given by one team, who reported a drama therapist, an art therapist and a speech and language therapist. One (1.8\%) team included counsellors. The roles for any of these workers within their teams were not established in this study. Administrative support for these teams was not enquired about.

A total of $33(60 \%)$ of the teams reported carrying out some form of training for prison staff. How this training was delivered was not enquired about in this study. Training offered was most often described as mental health awareness training. Two teams reported regular involvement in assessment care in custody and teamwork training, two offered involvement as part of staff induction, two teams provided training in the management of self-harm, one team offered training in attachment theory and one team had a rolling modular programme of training covering the recognition and initial, wing-based, management of all major psychiatric problems.

\section{Discussion}

A Hansard report in $2007^{6}$ reported that there were PMHITs operating in 102 prisons in England and Wales. This suggests that the list of 97 PMHITs compiled by Staffordshire PMHIT is likely to have captured the great majority of those teams in operation. The response rate of over $50 \%$ of teams, covering about $60 \%$ of prisons where such teams operate, for an unsolicited questionnaire is high; however, it is by no means certain that those who replied are representative of all teams, although such a high response rate means that the results need consideration in themselves.

Team make-up is disparate, and consequently appears unlikely to conform to any clear model of structure or function. Similarly, with the exception of the Category A estate, there is little convincing relationship between the amount of provision and the size of the prison as judged by operating capacity, although neither size nor category of prison are necessarily a firm predictor of the level of morbidity. Future research could usefully look at measures of prisoner turnover or 'churn' and levels of need - likely to be particular issues in the Category B estate.

Forensic psychiatry makes up over $50 \%$ of available input. Most psychiatric disorders and their management within the prison estate can be addressed by appropriately experienced and supported generalists and it is arguable that the more specialist skills of forensic psychiatrists be reserved for specific sets of patients presenting particular issues of risk or complexity.

Psychiatric provision almost universally falls short of that recommended and there appears to be little relationship between that provision and likely workload, save that provision increases in the Category A estate with size of prison, that provision increases as security increases and the women's estate is on average better served. Category A prisons tend to be near or served by well-established departments of forensic psychiatry, in turn linked to academic institutions, and the greater provision in the Category A estate may well reflect that, rather than any evidence of a coherent plan for commissioning and delivering psychiatric services to prisons. Indeed, it is our view that the evidence presented in this paper suggests the opposite - that services have developed piecemeal, with no clear standards and marked inequity of provision. Further concern arises when looking to the future, with new commissioning structures and processes on the horizon there is no certainty whatsoever that more resources will flow to this needy population. Indeed, the opposite seems likely. There is now a pressing need to develop and articulate a sustainable model of mental healthcare for prisoners, recognising the level of morbidity and going further than the current situation to provide equitable access and care. Whether the Royal College of Psychiatrists guidelines are a realistic target for staffing is a moot point, but there is no other benchmark currently to aim for. It would be a reasonable focus for research to determine a model or models of service provision, including staffing levels, associated with improved outcomes.

\section{Acknowledgements}

Many thanks to Gemma Mason of Staffordshire PMHIT.

\section{Appendix}

\section{Prison categorisation}

Prison categorisation in the male estate (note: female prisoners are categorised into 'open' or 'closed' conditions only). 
According to the prison service: 'Prisoners must be categorised objectively according to the likelihood that they will seek to escape and the risk that they would pose should they do so'?

Category A Prisoners whose escape would be highly dangerous to the public or the police or the security of the state and for whom the aim must be to make escape impossible.

Category B Prisoners for whom the very highest conditions of security are not necessary, but for whom escape must be made very difficult.

Category C Prisoners who cannot be trusted in open conditions, but who do not have the resources and will to make a determined escape attempt.

Category D Prisoners who can be reasonably trusted in open conditions.

\section{About the authors}

Nick Kosky is a consultant psychiatrist and medical director, Dorset Community Health Services, Forston Clinic, Dorchester. Clifford Hoyle is an offender mental health development manager, Offender Health South West, Bristol.

\section{References}

1 HM Prison Service \& NHS Executive Working Group. The Future Organisation of Prison Health Care. Department of Health, 1999.

2 Department of Health \& HM Prison Service. Changing the Outlook: A Strategy for Developing Mental Health Services in Prisons. Department of Health, 2001.

3 Royal College of Psychiatrists. Prison Psychiatry: Adult Prisons in England and Wales (College Report CR141). Royal College of Psychiatrists, 2007.

4 Office for National Statistics. Psychiatric Morbidity among Prisoners in England and Wales. ONS, 1997 (http://www.statistics.gov.uk/ STATBASE/Product.asp?vlnk=2676).

5 Department of Health. Improving Health, Supporting Justice: The National Delivery Plan of the Health and Criminal Justice Programme Board. Department of Health, 2009.

6 Daily Hansard. Written Answers 9 January 2007. Hansard, 2007 (http:// www.publications.parliament.uk/pa/cm200607/cmhansrd/cm070109/ text/70109w0018.htm).

7 HM Prison Service. Categorisation and allocation. Prison Service Order no. 0900. HM Prison Service.

\title{
Patients' knowledge about treatment for opiate dependence
}

\author{
Paula Alves, ${ }^{1,2}$ Adam Winstock ${ }^{3}$
}

The Psychiatrist (2011), 35, 448-453, doi: 10.1192/pb.bp.111.034546

\begin{abstract}
${ }^{1}$ European Monitoring Centre for Drugs and Drug Addiction, Portugal: ${ }^{2}$ Centre for Research and Social Intervention, Lisbon University Institute, Portugal; ${ }^{3}$ South London and Maudsley NHS Trust and Institute of Psychiatry, Kings College London, UK

Correspondence to Paula Alves (paulagomesalves@hotmail.com)

First received 11 Mar 2011, final revision 5 Jul 2011, accepted 2 Aug 2011
\end{abstract}

Aims and method A cross-sectional survey was conducted to assess patient knowledge and information provision about opioid substitution treatment among individuals with opiate dependence receiving treatment at four treatment centres in South London.

Results In total 118 people were recruited to the study. Participants answered a mean of 14 out of 34 questions assessing a range of factors such as medication, blood-borne viruses and overdose correctly. Participants overestimated their performance on average by almost $40 \%$. Individuals with a history of previous treatments scored significantly higher than those in their first treatment episode. The majority reported having been given written information on most of the topics assessed.

Clinical implications The results of this study highlight the need to improve education about opioid dependence and its treatment. Poorly informed patients are unlikely to make optimal treatment choices. Improving patients' knowledge and understanding about treatment may lead to better engagement, retention, treatment adherence and, ultimately, better health outcomes.

Declaration of interest None.
Opioid dependence is associated with high rates of psychiatric and physical illness, with significant impacts on the wider community through health costs, crime, blood-borne viruses and family disruption. ${ }^{1,2}$ There are approximately 140000 people on opioid substitution treatment in the UK, with a similar number out of treatment. Buprenorphine and methadone are both evidenced pharmacotherapies that have been consistently 